\title{
BREVES NOTAS SOBRE O PANOPTISMO LINGÜIISTICO*
}

\author{
Roberto Leiser Baronas**
}

Não é possível falar de qualquer coisa. nem atribuir a qualquer um o terrivel poder de enunciar. $\dot{E}$ um mundo dominado por um duplo interdito: quanto ao objeto

e quanto ao sujeito do enunciado. ${ }^{1}$

Michel Foucault

RESUMO: Este texto objetiva mostrar como a midia brasileira, nos seus mais diversos suportes, especialmente no final do século passado, vem produzindo determinadas práticas discursivas com o fim último de homogeneizar o português brasileiro. Para tanto, analisam-se discursivamente alguns textos que circularam nos principais jornais, emissoras de TV e revistas brasileiras, nos últimos cinco anos, versando sobre a questão dos "erros de português". Fundamentado nas idéias de Bentham. Foucault, Pêcheux, Bourdieu e Alain-Miller, esse estudo conclui que a midia funciona como uma máquina panóptica, pois enquanto esta disciplina os

* Uma versão bastante modificada deste texto fol apresentada em forma de comunicação oral individual durante o IV Encontro do CelSul - Círculo de Estudos Lingüisticos do Sul, realizado na UFPR - Curitiba, no período de 16 a 17 de novembro de. 2000 .

** Universidade do Estado de Mato Grosso - Unemat campus de Alto Araguaia.

1. Grifos nossos. 
sujettos pela vigilância contînua aquela institui sutilmente modos disciplinares de proceder lingüisticamente.

PALAVRAS-CHAVE: Midia; panoptismo; diversidade lingüística; discurso.

\section{1. "Primeiras" palavras: o Argos Panopticon}

A ntes de mostrar como a mídia institui modos discipliaté pela ilusão de completude do sujeito, ${ }^{2}$ tentando produzir um efeito de coerência nesse texto, seja necessário recuperar historicamente o que é e como se constituiu, inicialmente, a lenda do Panopticon e, depois, a sociedade do panoptismo.

Segundo o Dicionário de mitologia, da Editora Cultrix, Argos Panopticon era um gigante, filho de Arestor, que em algumas versões possuía um único olho, em outras, quatro: dois na frente $\mathrm{e}$ dois atrás. E ainda em outras the são atribuídos cem olhos. Ele, segundo a mitologia grega, foi o responsável pela libertação da Arcádia de um feroz touro que devastava o país. Matou um dos sátiros, causador de inúmeros prejuizos aos arcádios, roubando rebanhos. Foi também o responsável pela morte de Esquidna, a filha monstruosa de Géia e Tártaro. Por esses e outros feitos, Hera o incumbiu de vigiar a vaca lo, da qual sentia ciúmes com Júpiter. Argos, graças a seus múltiplos olhos, vigiava lo com grande eficiência. Mesmo dormindo, o gigante permanecia com metade de seus cem olhos abertos. Entretanto, Zeus ordenou que Hermes libertasse o pobre animal, e assim o fez. Há controverrsias na maneira como Hermes matou o gigante de cem olhos. Em algumas versões, conta-se que Argos teria sido morto com uma pedra atirada de longe. Em outras,

2. Ver a esse respeito Pêcheux (1988). 
que o enviado de Zeus teria feito com que Argos Panopticon adormecesse, tocando a flauta de Pã. Depois de cair em sono profundo, Hermes o teria matado. Diz a lenda que, em agradecimento a seus serviços, Hera tirou-lhe os olhos e os espalhou pela cauda do pavão, imortalizando- $\mathrm{O}_{s}$

\section{Bentham e o Panopticon}

Jeremy Bentham, filósofo e jurisconsulto inglês, a partir da idéia de vigilância contínua, metaforizada no mito grego do Argos Panopticon, elaborou um projeto arquitetônico, o qual denominou de Casa de Inspeção ou Elaboratório. Esse projeto foi escrito no outono de 1787, em Crecheff, na Rússia Branca, durante uma visita de Jeremy a seu irmão Samuel, na forma de vinte e uma cartas. Essas cartas foram endereçadas ao jornal inglês St. James Chronicle, por ocasião de um concurso instituido por esse jornal para escolha de um projeto de construção de uma nova prisão para Midllesex. Ouçamos o próprio Bentham enunciar a respeito:

Para dizer tudo em uma palavra, ver-se-á que ele [estabelecimento de inspeção] é aplicável, penso eu, sem exceção, a todos e quaisquer estabelecimentos nos quais, num espaço não demasiadamente grande para que possa ser controlado ou dirigido a partir de edificios, queira-se manter sob inspeção um certo número de pessoas. (Benttham, 2000: 17)

Trata-se de um edificio circular com uma torre no centro e na circunferência as celas. Entre a circunferência e o centro, uma zona intermediária. Em cada uma das celas, na circunferência que dá para o exterior, há uma janela que, embora deixe entrar o ar e a luz, impede que se veja o exterior dessas celas. Há também em cada uma delas, no interior, uma porta totalmente gradeada de modo a facilitar que o ar e a luz cheguem até o centro. 
Dos apartamentos da torre central, podem-se ver as celas. Contudo, alguns anteparos impedem que se vejam esses apartamentos desde as celas. Um muro bastante alto cerca o edificio todo. Entre os dois há uma área vazia que possibilita o trânsito do inspetor. Não há como entrar ou sair do prédio sem que as pessoas sejam vistas. Para isso só uma via é disponivel.

Sumariando, diriamos que esse prédio se constitui num dispositivo de vigilância ininterrupta dos indivíduos. Nada, ninguém. escapa do olhar onividente e invisivel do Panóptico. Seu maior ardil consiste no fato de que pode ver - ou criar a ilusão disso - sem ser visto. A esse respeito nos diz Miller (2000: 78): “a vigilância confisca o olhar a sua fruição, apropria-se do poder de ver e a ele submete o recluso. No edificio opaco e circular é a luz que aprisiona".

\section{Foucault e a sociedade do panoptismo}

Segundo Michel Foucault, em $A$ verdade $e$ as formas juridicas, Jeremy Bentham, muito mais do que Marx, Nietzsche ou Freud, é quem deveria ser reverenciado como um dos grandes pensadores da humanidade, pois a sua máquina panóptica se constitui na descriçāo mais precisa das formas de poder existentes atualmente na nossa sociedade. Um projeto arquitetônico que "permite um tipo de poder do espírito sobre o espirito; uma espécie de instituição que deve valer para escolas, hospitais, prisões, casas de correção, hospícios, fábricas etc. (Foucault, 1999: 87).

Contudo, para esse filósofo francês, nem sempre o mundo ocidental viveu sob a égide do panoptismo. Essa idade da ortopedia social só se instaura na Europa a partir da segunda metade do século XVIII. Até então, o que nós tínhamos era uma sociedade do inquérito, "uma forma política, uma forma de gestão, de exercício do poder que, por meio da instituição judiciária, veio a ser uma 
maneira de autenticar a verdade, de adquirir coisas que vão ser consideradas como verdadeiras e de as transmitir" (Foucault, 1999: 78).

A formação da sociedade disciplinar, no entendimento de Foucault, é caracterizada por dois fatos: a Reforma e a reorganização do sistema judiciário e penal de diferentes paises da Europa. Há, com isso, uma mudança no conceito do que é crime, e por conseguinte, do que é ser criminoso. Se na sociedade do inquérito, o crime era concebido como uma falta religiosa ou moral, e o criminoso como autor dessas possiveis faltas, na sociedade disciplinar, o crime passa a ser conceituado como um dano social, e o criminoso como alguém que danifica, prejudica a sociedade ou, em termos foucaultianos, como o "inimigo social".

Assim, para o autor de $A$ arqueologia do saber, toda a penali= dade do final do século XVIII e início do século XIX passa a ser um controle, cuja função não é mais única e tão-somente punir os individuos, mas, especialmente, corrigir suas virtualidades. $O$ individuo é, de certa forma, punido não só pelo que faz, porém pelo que poderia vir a fazer. Vigia-se continuamente o indivíduo para que este não danifique o corpo social.

Essa vigilãncia, além de reparar o mal, deve impedir que infrações semelhantes possam ser cometidas. Institui-se aqui a noção de periculosidade, ou seja, a sociedade considera o individuo não só por seus atos praticados, mas pelas suas virtualidades. "Entramos assim na idade [...] da ortopedia social. É a idade do controle social". (Foucault, 1999: 86).

Constitui-se então, para o homem de As palauras e as coisas, o panoptismo:

uma forma de poder que se exerce sobre os individuos em forma de vigilância individual e continua, em forma de controle de punição e recompensa e em forma de correção, isto é, de formação e transformação dos individuos em função de certas normas. (Foucault, 1999: 103) 
Ainda no entendimento desse autor, essa forma de poder baseada no controle, na vigilância, na correção e no exame do indivíduo se transforma em um saber-poder que possibilitará o surgimento não das grandes ciências de observação - ciências naturais - como no caso da sociedade do inquérito, mas ao que se chama hoje de ciências humanas. Ou seja, a partir do momento em que se passou a vigiar e a controlar continuamente os individuos, isso. produziu um conjunto de saberes que mais tarde se transformaram em objeto de estudo para essas ciências.

Desse modo, podemos observar que embora essa forma de poder - panoptismo - tenha se constituído no interior do campo juridico, depois de um determinado tempo, vai extrapolar esse campo e migrar para os mais diversos campos do saber de nossa sociedade. Dito de outro modo, o panoptismo se efetiva também em outras prâticas sociais, tais como as desenvolvidas nas instituições psicológicas, psiquiátricas, médicas, pedagógicas, entre outras. Vivemos hoje "em uma sociedade onde reina o panoptismo" (Foucault, 1999: 87).

\section{Panopticon midiático}

Atualmente, muitos são os estudos ${ }^{3}$ que tềm se debruçado sobre a influência da mídia no comportamento das pessoas. Para alguns desses estudos, a midia seria extremamente perniciosa, pois, por um conjunto de estratégias argumentativas e discursivas, induz as pessoas a determinados modos de procedimento. Para outros, no entanto, ela não teria todo esse poder. Mesmo preso nas armadilhas midiáticas, o sujeito não se deixaria sucumbir.

3 Referimo-nos, aqui, aos trabalhos de Wilsòn Brayn Key, A era da manipulação, a Hans Ulrich Gumbrecht, Modernizaçāo dos sentidos, e Wilson Dizard Jr., A nova mídia: a comunicaçāo de massa na era de informaçāo. 
Em nosso entendimento, a mídia funciona como uma espécie de usina geradora de memória(s). E essa geração de arquivo(s) se constitui num processo em que tanto se cristaliza quanto se apaga determinada memória. $\mathrm{O}$ apagamento ou a cristalização vai depender do aparelho ideológico para o qual a mídia está a serviço. Só a título de ilustração, recentemente, a mídia a serviço do governo do Estado do Paraná, por ocasião da venda do Banestado, veiculou o seguinte enunciado: "O Banestado foi saneado e agora está sendo desestatizado". Melhor para o Paraná (grifo nosso). No exemplo arrolado, podemos constatar, entre outras questōes, que a palavra privatização, comumente utilizada na venda de bens públicos, foi substituida pela palavra desestatizaçāo. De um ponto de vista semântico, seria uma simples troca de uma palavra por um sinonimo. Contudo, essa troca não é tão ingênua assim, pois se formos recuperar a historicidade dessas duas palavras, verificaremos que pelo fato de a grande maioria das privatizações realizadas no Brasil não ter surtido o efeito propagado pela mídia, construiu-se uma memória negativa em torno de privatização. Ao passo que desestatização não tem essa memória, de certa forma, virgem de sentido negativo.

Com o exemplo, podemos perceber que a mídia a serviço do Estado apagou uma memória e cristalizou em seu lugar outra. Assim, tal como Mariani, ${ }^{4}$ podemos dizer que a mídia "didatiza o mundo", isto é, imprime aos seus destinatários, como se fossem alunos, a sua interpretação objetiva do real. Desse modo, no mesmo proces-. so, enquanto cria a ilusão da literalidade dos sentidos, apaga a possibilidade de esses sentidos serem outros. O que era uma das possibilidades de significação foi (re)significado como o sentido único e verdadeiro.

4 Mariani (1998) nos diz que "o discurso jornalístico atua à semelhança de um discurso pedagógico em sua forma mais autoritária [...] pois no discurso jornalístico mascara-se um apagamento da interpretação em nome de fatos que falam por si $^{n}$. 
Essa didatização do mundo se constítui em um processo de domesticação dos sentidos, num panoptismo de nossas práticas significantes. Entre outras formas de comportamento, a mídia brasileira (nos seus mais diversos suportes) vem desenvolvendo, especialmente no final do século $\mathrm{XX}$, todo um trabalho de vigilância e de correção de nossas manifestações lingüísticas, instituindo modos disciplinares de proceder lingüisticamente. Há aí um claro objetivo de homogeneizar "o" português brasileiro, tendo como referencial um modelo de língua escrita que está contido nas gramáticas normativas de língua portuguesa. Interdita-se, assim, uma de nossas maiores riquezas culturais, a diversidade lingüística de nosso país.

Para comprovar o que enunciamos, basta ficarmos poucos minutos diante da TV e observarmos o apresentador de um programa destinado a jovens, Serginho Groisman, em uma vinheta chamada "Alô Brașil! Aqui tem educação", da Rede Globo, mostrar duas personagens em um suposto diálogo. Uma delas diz: "Vô pô o carro na garage". E a outra responde: "Não é garage. O certo é garagem". Ou lembrarmos de uma das cenas da novela global Andando nas nuvens, em que uma determinada personagem, ao ser presa por ter cometido um suposto furto, disse: "Sabe o que é, seu delegado, a gente somos inocente". Em seguida, o delegado responde: "Oh, infeliz, não é a gente somos, o certo é nós somos". Ou também, ler mos no artigo "Os pronomes e a Rüssia", de Diogo Mainardi, publicado na revista Veja, de 22 de março de 2001.

Nós, brasileiros, temos sérias dificuldades com pronomes. Os meus correspondentes, na maioria dos casos, começavam se dirigindo a mim, com um respeitoso 'senhor'. Depois de umas poucas linhas passavam informalmente para 'você'. A certa altura, escapava-lhes a segunda pessoa do singular, algo como o 'teu' filho.

Ou, ainda, o não menos ilustrativo exemplo de panoptismo lingüístico, presente no artigo intitulado "Português ou caipirês", 
de Dad Squarisi, publicado no Diário de Pernambuco, em 15 de novembro de 1998: "Falamos o caipirês. Sem nenhum compromisso com a gramática portuguesa. Vale tudo: eu era, tu era, nós era, eles era. Por isso, não fazemos concordãncia em frases como 'Não se ataca as causas' Ou 'Vende-se carros'". Poderíamos multiplicar os exemplos, mas acreditamos que os enunciados sejam suficientes para ancorar nossa argumentação.

Os quatro exemplos arrolados, veiculados em diferentes suportes midiáticos, são bastante elucidativos do que estamos chamando de panoptismo lingüístico: um processo de disciplinamento língüistico do povo brasileiro, com base num modelo de língua contido nas gramáticas normativas do português. Sutilmente, a mídia vem fazendo circular determinados discursos que versam sobre um saber lingüistico com o intuito de aniquilar toda a nossa diversidade lingüística. Parece-nos que a mídia - pegando carona no discurso de preservação do meio ambiente - vem realizando todo um trabalho de "despoluição" da língua padrão. Ou, em termos de Patrick Seriot, vem desencadeando toda uma ecologia lingüística. Ecologia essa que parte de uma premissa falsa, pois tem como dado o "mito" da homogeneidade da língua portuguesa falada no Brasil.

A mídia, a partir de certas determinações sociais, históricas e ideológicas, produz uma ilusão da realidade "que permite aos seus destinatários produzirem formas simbólicas de representação da sua relaçāo com a realidade concreta" (Gregolin, 1997: 47). Com efeito, a mídia constrói uma representação da lingua padrão como um objeto a ser consumido, como um bem simbólico que é desejado incondicionalmente por todos, uma vez que já se legitimou em nossa sociedade que os que não falam de acordo com a norma padrão falam "errado" e isso não possibilita "a tão almejada ascensão social”. A esse respeito, deixemos Possenti (1993: 120-1) enunciar:

A história secreta e silenciosa de um povo, se fosse escrita, nos revelaria maiores crueldades como os que sequer falam 
em certas circunstâncias, por serem considerados (até por si mesmos como fruto de uma ideologia da forma lingüística), incapazes de falar. E quando falam, o preço que pagam é alto em chacotas, perda de oportunidades de trabalho e de certos espaços sociais, reservados aos que dominam a "boa linguagem".

A língua padrão oferecida "gratuitamente" pela mídia como um objeto de consumo altamente desejável pelos que não a possuem se constitui em uma das mais perniciosas violências simbólicas que existem em nossa sociedade, pois faz com que os sujeitos rejeitem as suas próprias práticas discursivas - avaliadas como inferiores, como não-lingua - em favor de um modelo de comportamento lingüístico que não tem nada a ver com sua identidade cultural. Dito de outro modo, essa violência faz com que os sujeitos fiquem expropriados de sua própria lingua, conseqüentemente, de sua cultura.

Éjustamente essa extrema valorização da língua padrão como álgo positivo que possibilita que os sujeitos se tornem cúmplices de sua própria submissão lingüística. A esse respeito nos diz Bourdieu (1998: 38):

O reconhecimento da legitimidade da lingua oficial não tem nada a ver com uma crença expressamente professorada, deliberada e revogável, nem como um ato intencional de aceitação de uma "norma". Através de um lento e prolongado processo de aquisição, tal reconhecimento se inscreve em estado prático nas disposiçōes insensivelmente inculcadas pelas sançōes do mercado lingüístico [...] às possibilidades de lucro material e simbólico que as leis de formação dos preços caracteristicos de um determinado mercado garantem objetivamente aos detentores de um certo capital lingüistico. 


\section{Panoptismo lingüístico: seus a priori históricos}

Após refletir sobre essa verdadeira epousér da mídia com o panoptismo lingüístico, agora tentamos compreender minimamente qual(is) seria(m) o(s) a priori histórico(s) - em termos foucaultianos - que permitiu(ram) que se construísse, no final do século $X X$, um conjunto de práticas discursivas e não-discursivas que defendem o uso de um saber lingüístico baseado no modelo da norma-padrão do português. Ou seja, tento compreender por que foi possivel o aparecimento desse verdadeiro controle lingüístico, de certa forma, mais ou menos, nas palavras do bom e velho Freud, "uma espécie de agência interna [cotidianamente, edificada em nossas cabeças pelos defensores do idioma pátrio uno, homogêneo] para vigiar [nossas manifestaçōes lingüísticas], tal qual uma guarnição numa cidade conquistada". Enfim, quais as condições que possibilitam(ram) a sua irrupção?

Para que nosso interlocutor não pense que "beliscamos azulejos", basta, mais uma vez, deixarmos as comportas de nossa memória discursiva se abrirem e nos lembrarmos da infinidade de discursos que foram produzidos e veiculados pela mídia nos seus mais diversos suportes, nestes últimos anos, versando sobre a questão dos erros de português e a invasão de estrangeirismos. Pensamos que dificilmente deixaríamos de encontrar - caso fizéssemos uma pesquisa com tal objetivo - um único meio de comunicação de massa, nos mais longínquos municípios brasileiros, que deixou de dedicar alguns minutos ou espaços de sua programação ou edição diária ou semanal para enunciar a respeito.

Diante dessa constelação de discursos, nos perguntamos: o que leva(ou) tantas pessoas - quer sejam especialistas ou não - a enunciarem sobre esse assunto? Como tantos sujeitos das mais diferentes classes sociais, que vêem o mundo de diferentes mirantes, em um mesmo momento histórico, foram levados a produzir um conjunto de enunciados que se inscrevem numa única "forma- 
ção discursiva" (Foucault, 1993). Enunciados que advogam desde a "nostradâmica profecia" do fim do português (Veja, 5.4.2000) até a legitimação de um Movimento Nacional em Defesa da Lingua Portuguesa.

Marcos Bagno, em sua Dramática da lingua portuguesa (2000: 108-9), nos oferece uma boa hipótese para explicar essa "neogramatiquice conțemporânea":

pode ser que o atual movimento neogramatiqueiro se prenda a uma necessidade de buscar uma linguagem pura, um código sagrado ou secreto que permita uma comunicação mais perfeita. Descrente dos métodos tradicionais de ensino (tal como há descrédito das grandes religiōes tradicionais), os novos peregrinos recorrem aos mestres iluminados do idioma, que têm as fórmulas de acesso ao nirvana da língua padrão. De fato, os comandos paragramaticais têm função similar aos dos livros e outras manifestações multimidiáticas de auto-ajuda: mostrar um caminho diferente, melhor, que permita ao indivíduo subtrair-se ao caos da modernidade estressante.

Uma outra boa hipótese é a de que, com a crescente ascensão da esquerda ao poder político do país, seu discurso contrário à globalização conquistou um certo espaço na mídia. Com isso, a preservação da língua portuguesa "única", "homogênea" passou a se constituir em mais um dos objetos do discurso nacionalista contrário à globalização, compreendida por esse tipo de díscurso como um processo que seria extremamente pernicioso para a nossa cultura e, por conseguinte, sendo a língua um produto da cultura, ou mantendo com ela uma relação de intrincamento, o meio pelo qual se registra(ou) a história do nosso povo, a globalização estaria também aniquilando a nossa lingua.

Mais uma boa hipótese, que tem a ver com a anterior, é a de que, por ocasião das comemorações dos quinhentos anos do descobrimento/achamento do Brasil, a mídia construiu todo um discur- 
so ufanista, de exaltação quase lírica das "coisas brasileiras", produzindo assim um conjunto de outras práticas discursivas e nãodiscursivas que defendem a lingua portuguesa "única", "homogênea" como sinônimo de brasilidade.

Ainda uma outra boa hipótese é a de que, com as constantes agressôes que o homem moderno vem fazendo ao meio ambiente, construiu-se uma verdadeira episteme em que a reflexão biológica passou a ser dominante. Assim, em "tempos do ecologicamente correto" tanto a preservação do meio no qual vivemos quanto a preservação da cultura se constituíram numa necessidade vital para o ser humano. Com efeito, do mesmo modo que é preciso despoluir o planeta, é necessário "despoluir a lingua" Sériot (1999). Irrompe, então, uma verdadeira campanha "ecolingüística" contra as variantes não-padrão, consideradas pelos puristas como uma espécie de "lixo atômico-lingüístico".

Pensamos que as hipóteses anteriormente arroladas, embora sejam bastante pertinentes, não conseguem dar uma explicação mais ampla do fenômeno em análise: Para tanto, acreditamos que seja necessário perscrutar uma outra hipótese. Estou me referindo a uma idéia prolífica que foi defendida no ensaio "O castelo encantado", de autoria do professor Sérgio Paulo Rouanet, atualmente na Universidade de Brasília, publicado no caderno "Mais!" da Folha de S. Paulo, no dia 7 de janeiro de 2001.

Nesse ensaio, o autor enuncia que à semelhança de Dom Quixote - cuja personalidade foi moldada com base em um único grupo de referência, "a comunidade imaginária dos cavaleiros andantes”, reduzida, portanto, a uma identidade única - nós (homens e mulheres modernos) estamos vivendo, neste final e inicio de um novo século, em um momento em que prevalece o "pensamento uni-identitário". Desse modo, as relaçőes "interpessoais foram subs tituídas por relaçôes entre diferenças, congeladas em identidades: os seres humanos deixaram de dialogar enquanto sujeitos e passa- 
ram a se confrontar enquanto negros, judeus, mulheres ou homossexuais". E isso, segundo Rouanet, graças a uma mudança de natureza do pensamento identitário. Se antes era o ser socioeconômico quem determinava a consciência, agora quem a determina é o ser cultural. "A cultura adquire um carâter sacrossanto, e por isso as identidades se tornam imperiosas". Assim, ao se tornar um ser cultural, o homem passou a ver o mundo a partir do horizonte de visibilidade de sua cultura. Contudo, somente "uma identidade [...] toma o poder, expulsando as demais e recalcando a identidade universal. A identidade étnica, ou de língua, ou de religião passa a ter prioridade sobre a identidade humana" (grifo nosso).

Pode ser que o "uni-identitarismo" explique por que tantas pessoas se matam, matam e são mortas em nome de líderes políti$\cos$ e/ou religiosos tanto no Ocidente quanto no Oriente, por que jovens de classe média alta covardemente ateiam fogo em um índio Pataxó em Brasília, ou ainda, por que jovens que se autodenominam skinheads brutalmente assassinam um homossexual em São Paulo. Caso tivêssemos mais tempo e espaço, poderiamos multiplicar os exemplos.

Acreditamos que esse "pensamento uni-identitário" seja tambểm a razão mais plausivel para explicar o panoptismo lingüístico contemporâneo, uma vez que esse tipo de pensamento se constituiu numa verdadeira "configuração epocal" que vem condicionando boa parte de nossas prâticas discursivas e não-discursivas. Em outras palavras, aproveitando-nos da imagética biológica, o "uniidentitarismo" é o solo fértil do qual brotam os enunciados-sementes que tentam transformar a imensa floresta em que reina, entre outras variedades, a biodiversidade lingüistica num extenso deserto verde no qual predominaria uma única espécie, a dinossáurica norma-padrão do português. 


\section{6. (In)Conclusões preliminares}

Convêm enunciar que, diferentemente de outros discursos, cuja produção é muito mais "controlada, selecionada, organizada e redistribuida por certo número de procedimentos que têm por finalidade conjurar seus poderes e perigos, dominar seu acontecimento aleatório" (Foucault, 1971: 8-9), os discursos que dizem avaliativamente a lingua no Brasil são de certa forma menos vigiados. Ou seja, todos falam alguma coisa ou têm um palpite sobre a lingua, têm uma espécie de consciência lingüística sobre o seu e o falar dos outros. O que não acontece, por exemplo, com os discursos que dizem a Física. Só os especialistas desse campo do saber é que têm o direito legitimado de enunciar a respeito.

Talvez isso se explique porque a língua não seja vista como um objeto digno de estudo, já que os compêndios gramaticais trazem tudo a seu respeito. Qualquer dúvida com relação à língua é sá consultar uma gramática. E, também porque, como diz Faraco (2001), "a lingüística [...] de modo diferente de outras ciências, não conseguiu ultrapassar minimamente os centros de pesquisa e se difundir socialmente para fazer ressoar o discurso científico". Ade mais, temos na grande midia brasileira, desde jogadores de futebol famosos, tais como Ronaldinho e Tostão, até o mais simples cidadão falando sobre um saber lingüístico. Algo do tipo: "não se diz mortandela, o certo é mortadela" ou "o gaúcho tem um sotaque diferente do nordestino". Em contrapartida, não temos, salvo em meteóricas aparições, um lingüista enunciando acerca das mais diversas abordagens que se dedicam a estudar cientificamente a(s) lingua(s) e, muito menos, sobre os resultados que tais estudos vêm produzindo.

Feita essa pequena, mas necessária digressão, voltemos ao objetivo primordial deste texto. Para tanto, é necessário que façamos uma viagem na história do Brasil, retornando a alguns séculos atrás. Durante quase 250 , ao lado da língua portuguesa eram fala- 
das mais de uma centena de outras linguas. Dentre elas estava a língua geral - uma espécie de tupi gramatizado e ensinado pelos jesuítas. Todas essas linguas, na sua grande maioria ágrafas, conviveram mais ou menos harmonicamente com o português até o século XVIII.

A partir de então, inicia-se uma verdadeira cruzada contra, sobretudo, a língua geral, culminando em 1757 , por parte do marquês de Pombal, com sancionamento do Diretório, um conjunto de medidas políticas que proibiam o uso dessa língua na colônia, institucionalizando a lingua portuguesa como a língua da cultura, da administração, da política e do ensino do/no Brasil. Assim, a língua geral que até então possuía uma espécie de salvo-conduto, caỉ numa situação de marginalidade e de clandestinidade. Deixemos o próprio Pombal enunciar a respeito:

para desterrar este perniciosíssimo abuso, será um dos principais cuidados do Diretório estabelecer nas, suas respectivas povoações o uso da língua portuguesa, não consentindo por modo algùm que os Meninos e as Meninas, que pertencem as escolas, e todos aqueles indios que forem capazes de instruçāo nesta matéria, usem da lingua Geral, mas unicamente a Lingua Portuguesa, na forma que S. M. tem recomendado em repetidas Ordens, que até agora não se observaram, com total ruína temporal e espiritual do Estado.. (Apud Cunha, 1979 - grifos nossos)

Provavelmente, uma das razões para o sancionamento do Diretório, por Pombal, esteja diretamente relacionada com o poder que os jesuítas possuiam na colônia. Com efeito, a proibição do uso da lingua geral e a conseqüente institucionalização do uso da língua portuguesa como a lingua ideal, legal e nacional do/no Brasil provocaram o enfraquecimento do poder jesuitico e o fortalecimento do poder da metrópole, culminando com a expulsão dos jesuítas, em 1759. O que implica dizer que a proibição do uso da língua geral não se baseou em critérios lingüisticos, mas puramente po- 
líticos. Ou seja, o processo de unificação e normatização do português desencadeado por Pombal baseou-se única e tão-somente nos jogos de poder entre os jesuítas e a metrópole. Interessante observar que esses jogos de poder geraram diversos saberes: um deles é o panoptismo lingüístico.

Diante do anteriormente enunciado, pensamos que seja perfeitamente plausivel postular que a obrigatoriedade do uso da lingua portuguesa como língua oficial do/no Brasil tenha sido a faísca que incendiou o capim discursivo que diz avaliativamente o português. De lá para cá, o português europeu escrito passou a ser concebido como o modelo ideal, legal e nacional de língua. Ao passo que tudo o que fosse diferente desse modelo passou a ser visto e reprimido como erro, como ruim, como ineficiente etc.

Mais discursivamente falando, diriamos que o Diretório de Pombal se constitui como um acontecimento discursivo, que rompe uma memória já sedimentada, fundando uma nova discursividade. Com isso, construiu-se a imagem de uma lingua ideal, legal e nacional para o Brasil, que, por sua vez, passou a engendrar os discursos que dizem avaliativamente a lingua até nos nossos dias. Paralelo a esse processo, silenciaram-se os discursos contrários, colocando-os numa situação de transgressão, de conspurcação, de falta de brasilidade. Neste momento, como diz Gallo (1992); estabelece-se entre norma lingüistica e nacionalidade uma relação direta e paradoxal: "quanto mais de acordo com as normas da lingua disciplinar (a portuguesa), mais brasileiro".

Ousaríamos dizer que é esse o raciocínio que sustenta toda a argumentação dos discursos que dizem avaliativamente a língua no Brasil até hoje, uma vez que, para ele quem "transgride as normas do português padrão, deixa de ser brasileiro". Contudo, se fizermos uma análise um pouco mais profunda desse raciocínio, constataremos que ele é falacioso, visto que, de um ponto de vista lógico, entre estar de acordo com as normas da língua portuguesa padrão 
e ser brasileiro não exíste correspondência direta, uma implicação necessária, isto é, não existe uma relação de causa e conseqüência. Ser ou não ser brasileiro tem a ver com critérios de naturalidade ou habitação, ou seja, ser nascido ou estar morando no Brasil e não com critérios de uso da língua portuguesa padrão. Posso perfeitamente ser brasileiro sem sequer saber um palavra em português.

Dando um efeito de fim a este texto, diriamos que, se o que levantamos está correto, os discursos que dizem avaliativamente a língua no Brasil estão fundamentados num raciocínio falacioso, portanto eles partem de um falso problema e, partindo de um falso problema, as conclusões decorrentes não são pertinentes, válidas.

\begin{abstract}
The present essay has as the aim to show how braziliam media, in its more variable propops, has been producing certain discursive practice with the hindmost objective of annihilating every existing linguistic heterogeneity in Brazil, especially in this and of century. In order to do this, some textes are discoursively analysed, textes which were abrouad during the last yers in the main brazilian newspapers, broadcasting station television and magasines, discursing the matter of "portuguese misspelling". Based upon the ideas of Bentham, Foucault, Pêcheux, Bourdieu and Alain-Miller, this survey concludes that media operatis similary to "panoptic machine", for while the latter disciplines peoples by a continuos vigilance, the former subtly institutes disciplinary ways of linguistically proceeding.
\end{abstract}

KEYWORDS: Mas media; panoptism; linguistic diversity; discourse.

\title{
BIBLIOGRAFIA
}

Bentham, J. (2000) O Panöptico. Belo Horizonte: Autêntica, 
BAGno, M. (2000) Dramática da língua portuguesa: tradiçāo gramatical, mídia e exclusão social. São Paulo: Loyola.

Bourdieu, P. (1998) A economia das trocas lingüísticas. 2. ed. São Paulo: Edusp.

CunHA, C. (1975) Lingua portuguesa e realidade brasileira. Rio de Janeiro: Tempo Brasileiro.

Dicionário de Mitologia. (s.d.) Sāo Paulo: Cultrix.

FARACo, C. A. Guerra em torno da língua. Folha de S. Paulo, 25 mar. 2001. Mais!

Foucault, M. (1971) O homem e o discurso: a arqueologia de Michel Foucault: Rio de Janeiro: Tempo brasileiro.

. (1995) A arquelogia do saber. 4. ed. Rio de Janeiro: Forense Universitária.

Vozes.

(1987) Vigiar e punir: nascimento da prisão. 13. ed. Petrópolis:

- (1998) Microfisica do poder. 13. ed. Rio de Janeiro: Graal, . (1999) A verdade e as formas jurídicas. Rio de Janeiro: Nau Editora.

Gallo, S. L. O ensino da língua "materna" no Brasil do século XIX: a māe outra. In: Guimarães, E.; Orlandi, E. P. (Org.). (1996) Língua e cidadania: o português no Brasil. Campinas: Pontes.

Gregolin, M. do R. V. (1997) Discurso e memória: movimento na bruma da história. Cadernos da FFCH, Marília, v. 6, n. 2 ,

Mariani, B. S. C. (1998) O PCB e a imprensa: os comunistas do imaginărio dos jornais (1922-1989), Rio de Janeiro: Revan; Campinas: Ed. da Unicamp.

Miller, J.-A. A mãquina panóptica de Jeremy Bentham. In: Bentham, J. (2000) O Panóptico. Belo Horizonte: Autêntica.

Pêcheux, M. (1998) Semântica e discurso: uma crítica á afirmaçāo do ôbvio. Campinas: Ed. da Unicamp. tes. . (1990) O discurso: estrutura ou acontecimento. Campinas: Pon*

Possentr, S. (1993) Discurso, estilo e subjetividade. São Paulo: Martins Fontes.

Rouanet, S. P. O castelo encantado. Folha de S: Paulo; 7 jan. 2001. Mais! 
BARønas, Roberto Leiser. Breves notas sobre o panoptismo lingüístico

Seriot, P. Anamnésia da língua russa e a busca de identidade na Rússia: In: Indursky, F.; Ferreira, M. C. L. (1999) Os múltiplos territórios da análise do discurso. Porto Alegre: Sagra Luzzatto. 